\title{
Annual variability in sound acorn production was regulated by a generalist seed predator weevil in Quercus serrata
}

Kimiko Hirayama ${ }^{1 *}$, Kenta Mizo ${ }^{1}$, Manaka Tatsuno $^{2}$, Mizuki Yoshikawa², Chieri Tachikawa ${ }^{2}$

${ }^{1}$ Graduate School of Life and Environmental Sciences, Kyoto Prefectural University, Hangi-cho 1-5, Shimogamo, Sakyo-ku, Kyoto, Japan

${ }^{2}$ Faculty of Life and Environmental Sciences, Kyoto Prefectural University, Hangi-cho 1-5, Shimogamo, Sakyo-ku, Kyoto, Japan

${ }^{*}$ Corresponding author: Kimiko Hirayama

Email: khirayam@gmail.com

Tel \& Fax: +81757035682

\section{Acknowledgment}

We thank the staff of the Kamigamo Experimental Station, Kyoto University for their permission to use the forest for our study. We are grateful to Akihiro Sumida for advice for statistical analyses and critical reading of the first manuscript. We also thank the members of the laboratory for research assistance. This study was funded by JSPS KAKENHI Grand Number 18K05750. 


\section{Abstract}

2 Highly variable and synchronous seed production within a population ('masting') could be from

3 either synchronised high annual variability in floral initiation ('flower masting') or

4 synchronised floral abortion until maturity ('fruit maturation masting'). We investigated the

5 demographic processes of the female organs from flowering to seed maturity, including each

6 type of insect damage identified, in Quercus serrata in six individuals within a stand from 2014

7 to 2020, western Japan. Although the annual production of sound acorns was significantly

8 correlated with that of female flowers, the annual variability in sound acorn production within

9 an individual was significantly higher and their synchrony increased, compared to those of

10 female flowers. The annual production of female flowers was positively correlated with the

11 temperature difference in April between the previous and flowering years. However, their

12 fluctuation was low, which was neither affected by seed and flower production in the previous

13 year nor contributed to predator starvation. Key-factor analyses revealed that reproductive loss

14 due to oviposition and sap suction by Mechoris ursulus, a generalist seed predator weevil for

15 oak species, was the largest and most important factor that contributed to the annual variation

16 in the total pre-dispersal loss of $Q$. serrata. The survival rate from female flowers to sound 

usually termed 'masting', has been observed in many long-lived plant species (Kelly 1994, 31 Kelly and Sork 2002). Because masting requires plants to delay reproduction, it is assumed that

acorns was strongly predicted by the temperature in June, corresponding to the emergence of adult M. ursulus. This study suggests that highly variable and synchronous sound seed production can be proximately regulated by seed predation when the main predator is a generalist.

\section{Keywords}

annual variability in seed production, seed predator, oak species, masting

\section{Statements and Declarations}

We have no conflict of interest to declare.

\section{Introduction}

Highly variable seed production, which synchronises among individuals within a population,

masting occurs as a selective advantage through 'one or more economies of scales', such as 
predator satiation and pollination efficiency, in which an occasional large reproductive effort is

more efficient than regular smaller ones (Norton and Kelly 1988, Kelly and Sork 2002). In

contrast to the ultimate-level hypothesis, masting is regulated by proximate-level mechanisms,

such as responses to variability in internal resources and weather cues, which do not necessarily require ultimate-level benefits (Crone and Rapp 2014, Pearse et al. 2016). Identifying the factors that proximately produce variability in seed production would lead to an understanding the adaptive meaning of masting.

Pearse et al. (2016) suggested that the production of a mast seed crop can be the product of either high initial flower production ('flower masting') or high proportion of flowers maturing into seeds ('fruit maturation masting'). In flower masting, the success rate of pollination and maturation into fruit will be high during high-flowering years, induced by weather cues or resources. In fruit maturation masting, flower or seed abortion during predispersal stages, owing to factors not related to flowering size, e.g., weather condition during pollination and/or fruit growing, causes variation in seed crops, which may occur even in the absence of any selective advantage (Espelta et al. 2008, Perez-Ramos et al. 2010). In addition, Montesinos et al. (2012) reported not all mast flowering episodes resulted in mast seeding. 

production was larger than that of pollination failure, although both factors significantly

Therefore, to determine the real factors causing masting and their relative contribution, clarifying the demographic process of female reproductive organs from flowering to seed maturity in each individual within a population in the long term, together with the effects of weather and resources, would be needed.

For fagaceous species, whose masting behaviour has been reported in many previous studies (e.g., Sork et al. 1993, Kelly and Sork 2002, Shibata et al. 2002, Kon et al. 2005, Espelta et al. 2008, Perez-Ramos et al. 2010, Koenig and Knops 2014, Koenig et al. 2015, Pesendorfer et al. 2016, Schermer et al. 2019, Moreira et al. 2019), predation pressure on their female reproductive organs (i.e., acorns) is known to be high (Kon et al. 2005, Hirayama et al. 2017, Xiao et al. 2017, Bogdziewicz et al. 2018). Kon et al. (2005) investigated the relative contribution of pollination failure and insect predation to the annual fluctuation of seed crops for Fagus crenata by monitoring the female reproductive organs from flowering to seed maturity in five beech forests. They indicated that the effect of insect predation on seed affected fluctuations in seed production. As in their study, the quantitative evaluation of insect 
understanding masting behaviour in fagaceous species, although few studies have reported on it (Fukumoto and Kajimura 2005, Hirayama et al. 2017).

Previous studies indicated that pre-dispersal predation in fagaceous species occurs soon after flowering up to maturity by various insects and that oviposition by adult insects and predation by hatched larvae usually occur at specific periods during the pre-dispersal phase (Fukumoto and Kajimura 2001, Hirayama et al. 2017). Koenig et al. (2003) suggested that seed predator characteristics, such as size, mobility, abundance, lifespan, and degree of specialisation, act as selection pressures in the seed production patterns of plants. Therefore, distinguishing each type of insect damage and evaluating its effect on the demographic process during the predispersal stage might explain the real cause of fluctuations in seed production of fagaceous species. In this study, we investigated the demographic processes from flowering to seed maturity, including each type of insect damage identified, for six individuals of Quercus serrata within a forest stand from 2014 to 2020 . First, we analysed intra-individual variability and interindividual synchrony within a population in both annual flower and sound acorn production in relation to weather and resources, examined in previous studies as mentioned above. Second, 
key factor analyses were conducted to assess the relative importance of each demographic

82

factor that can contribute to annual fluctuations in sound acorn production during the predispersal stage in individuals. Based on these results, we proposed a novel mechanism affecting annual variability in seed production in plant species whose main seed predator during the predispersal stage is a generalist: insect predation can proximately induce highly variable and synchronous sound seed production within a population.

\section{Materials and Methods}

\section{Study site and species}

We conducted our study at the Kamigamo Experimental Station, Kyoto University $\left(35^{\circ} 4^{\prime} 21^{\prime \prime} \mathrm{N}\right.$, $135^{\circ} 45^{\prime} 43^{\prime \prime} \mathrm{E} ; 145 \mathrm{~m}$ a.s.1.) in western Japan, which has hot and humid summers and moderately cold winters. The rainy season occurs annually during the transition from spring to summer, from the beginning of June to the middle of July. Based on the data recorded from 1986 to 2015 at the station office $\left(142 \mathrm{~m}\right.$ a.s.l.), the mean annual temperature and precipitation were $14.7^{\circ} \mathrm{C}$ and $1578 \mathrm{~mm}$, respectively (Kamigamo Experimental Station, unpublished data). The forest soils were Inceptisol (Soil Survey Staff 2010) derived from Mesozoic sedimentary rocks 
(Geological Survey of Japan, AIST 2015). The study area was covered with a secondary forest dominated by Chamaecyparis obtusa, Q. serrata, Q. glauca, and Ilex pedunculosa. Q. serrata is a deciduous oak native to East Asia that belongs to the subgenus Quercus section Prinus (Iwatsuki et al. 2006). This species is widely distributed in temperate regions and is often found in secondary forests in Japan. Q. serrata is monoecious, anemophilous, flowers in spring (during late April and early May in the study site; K. H., personal observation), and requires one year to mature acorns. According to the observation of flower buds using a stereomicroscope, Hashizume et al. (2003) found that differentiation of primordia of staminate inflorescences within the buds occurred from late June to late August of the previous year of flowering, and pollen grains were formed in early or middle April of the following year. They also reported that the differentiation of pistillate flowers was initiated in early August of the previous year of flowering, perianth differentiation occurred in late August, young pistillate flowers grew rapidly in mid-April in the following year, and pistil differentiation was observed approximately 10 days before anthesis. After flowering, fruit development occurred until late September; first, the cupules, which enclose the acorns, develop and then enlarge, and after that, 

unpublished data). Mature acorns mainly fall in mid-October. 
We selected six $Q$. serrata individuals (diameter at breast height $(\mathrm{DBH}) \pm \mathrm{SD}, 35.4 \pm 6.8 \mathrm{~cm}$;

height, $18.4 \pm 2.2 \mathrm{~m}$; canopy area, $45.2 \pm 42.2 \mathrm{~m}^{2}$ ). These trees were within a natural stand

where a number of $Q$. serrata trees were mixed. Regarding fagaceous species within the stand,

Q. glauca, Q. sessilifolia, and Castanopsis cuspidata were also mixed to a lesser extent. We set

three seed traps $\left(0.5 \mathrm{~m}^{2}\right.$ surface area with a circular mouth) under the crown of each sampled

tree on 13 May 2014. Each seed trap was made of polyethylene cloth (mesh size, $1 \mathrm{~mm}$ ) and

positioned approximately $1.2 \mathrm{~m}$ above the ground. The contents of the traps were collected

twice a month from May 2014 to March 2021, and all female reproductive organs (both

pistillate flowers and acorns) of $Q$. serrata were sorted in the laboratory. We first classified the

organs into four categories based on the size (length and width of the organs) and the condition

of the organs: (A) sound (attaining mature acorn size [13 $\mathrm{mm}$ in length, $7 \mathrm{~mm}$ in width] with

sound cotyledons), (B) immature with no signs of damage (failing to attain mature seed size

and/or with undeveloped cotyledons, including pistillate flowers); (C) organs with some signs

141 of damage other than being broken (exhibiting a gnaw mark, a penetrating hole, larval frass,

142 deformation, and/or discolouration; mainly caused by insects), and (D) the organs that were

143 broken (mainly caused by vertebrate predation), as described by Hirayama et al. (2017). The 
organs classified into category (D) were low in our study system $(0-1.4 \%$ of all female

145 reproductive organs falling during one year in each tree). using a stereomicroscope. Based on larval faeces, feeding traces, penetration and oviposition scars, and/or larvae inside, we classified the damage into the following types: (a) sap suction by adult weevils, mainly by $M$. ursulus, (b) damaged by moth larvae, (c) oviposition by $M$. ursulus, (d) oviposition by weevils other than M. ursulus, mainly by K. rectirostris, (e) damaged by cynipid wasps, and (f) others, as described by Hirayama et al. (2017). In addition, we reared the larvae from the female reproductive organs and observed the feeding and/or oviposition patterns of the adults on the organs (K. H. personal observation). Based on this, we confirmed our classification of insect damage types. For each type of insect damage, the mean $\pm \mathrm{SE}$ of the length of the organs was recorded, which reflected the developmental stage of the organs

156 (Matsuda 1982, K. H. unpublished data). These measurements for each of the types of damage were as follows: (a) $5.82 \pm 0.06 \mathrm{~cm}$, (b) $9.13 \pm 0.28 \mathrm{~cm}$, (c) $13.29 \pm 0.13 \mathrm{~cm}$, (d) $12.11 \pm 0.29$ $\mathrm{cm}$, and (e) $4.64 \pm 0.06 \mathrm{~cm}$, respectively. They were determined to be statistically different from each other based on Tukey's multiple comparison test $(P<0.05)$ after conducting a linear mixed 
model (LMM) with the length of acorns as the response variable and each type of insect damage

161 as the explanatory variable, with each individual tree as a random factor.

164 Annual variability in the number of female flowers and sound acorns

165 We defined the sum of the number of female reproductive organs that fell into the seed traps

166 for each individual (total area, $1.5 \mathrm{~m}^{2}$ ) in a year (flowering to the end of the following March)

167 as the annual number of female flowers. To detect intra-individual variability in the production

168 of female flowers and sound acorns, we calculated the coefficient of variation for the annual

169 numbers of female flowers and sound acorns during the seven-year observation for each of the

170 six individuals $\left(C V_{i}\right)$ and their means $\left(\overline{C V}_{l}\right)$. To identify inter-individual synchrony in the

171 production of female flowers and sound acorns within a population, we calculated pairwise

172 correlation coefficients of the female flower and sound acorn numbers (both log-transformed

173 after adding 1 to reduce the correlation between the mean and the variance and avoid excluding

174 zero data) during the seven years for each pair of all individuals (Pearson's correlation

175 coefficient; $\left.r_{p}\right)$, and then obtained the means of all these pairs $\left(\overline{r_{p}}\right)$, as suggested by Koenig et 
al. (2003). To obtain $95 \%$ confidence intervals in $\overline{C V_{l}}$ and $\overline{r_{p}}$ values, we performed sets of 1000 bootstrap trials, in which the annual number of female flowers and sound acorns were randomly replaced from the observed values for each individual over a seven-year period. binomial error distribution to evaluate whether the annual number of sound acorns per individual is related to female flowers. The annual number of sound acorns (non-logtransformed) was designated as the response variable. The annual number of female flowers, which were log-transformed after adding 1, was the explanatory variable, and the individual tree was treated as a random factor. To explore the effect of the previous flower and/or acorn production per individual on their current amount, we also conducted GLMM analyses with a $\log$ link and negative binomial error distribution. The annual numbers of female flowers or sound acorns (non-log-transformed) in the year $\left(t_{i}\right)$ were designated as the response variables, whereas those in the year before $\left(t_{i-1}\right)$ were designated as the explanatory variables. These explanatory variables were log-transformed by the addition of 1 . Individual trees were treated as random factors. 
192 individual was related to pre-dispersal insect damage, we performed two GLMM analyses with

193 logit link and binomial error distribution, in accordance with Shibata et al. (2002). In the first

194 analysis, to examine whether individual-level predation satiation occurred in years with high

195 production of female flowers, the proportion of the female organs damaged by insects during

196 one year per individual was designated as the response variable, and the log-transformed annual

197 number of flowers per individual was the explanatory variable. In the second analysis, to

198 examine whether annual fluctuations in the production of female flowers per individual

199 contribute to the individual-level predator starving effect, the proportion of the female organs

200 damaged by insects during one year per individual was designated as the response variable, and

201 the log-transformed ratio of the annual number of female flowers per individual in the year $\left(t_{i}\right)$

202 to the year before $\left(t_{i-1}\right)$ was designated as the explanatory variable. In both analyses, the

203 number of broken acorns (mainly due to vertebrate predation) was excluded from calculating

204 the proportion of the female organs damaged by insects, and the individual tree was treated as

205 a random factor. When the annual number of female flowers per individual was zero, the data

206 were excluded from the analysis. 
Relationships between weather variables and the annual production of female flowers and

survival rate from female flowers to sound acorns

210 We obtained daily precipitation data and mean daily temperature (average of the daily

211 maximum and minimum values) from 2012 to 2020 from the Kamigamo Experimental Station

212 office. Weather variables were chosen considering the differentiation process of the

213 reproductive organs in flower buds, as mentioned above (Hashizume et al. 2003), for the

214 analyses of annual variability in female flower number per individual; monthly average

215 temperature (average of mean daily temperatures for one month), and precipitation from April

216 to September one year before flowering and from March to April in the flowering year were

217 considered. We also calculated the difference between a year and its previous year for all

218 variables, according to methods described by Kelly et al. (2013), who suggested that the

219 differential cue might cause masting behaviour. We checked for multicollinearity among all

220 variables using a variance inflation factor (VIF), where a VIF $>10$ was considered to indicate

221 multicollinearity (Quinn and Keough 2002). If one variable was highly correlated with another 
then performed GLMM models, which were a log link and negative binomial error distribution,

224 with the annual number of female flowers per individual (non-log-transformed) as the response

variable, each adopted weather variable as the explanatory variable, and the individual tree as

a random factor. We selected five weather variables based on a comparison of the models using the Akaike information criterion (AIC); the lower the AIC value, the better the model. We then created GLMM models based on a subset of the five selected variables. The best model was determined using the AIC value, as calculated from the R package MuMIn (Barton 2020), which calculates all possible models extracted from the full model. When there were models with fewer parameters whose $\Delta \mathrm{AIC}$ was $<2$ from the top model, we adopted the simplest model (with the fewest parameter) as the best model. This was because models with $\triangle \mathrm{AIC}$ between 0 and 2 were considered to have equivalent and substantial empirical support (Burnham and

234 Anderson 2002). For the analyses of survival rate from female flowers to sound acorns per individual per year, we chose average daily temperature and total precipitation during the flowering periods of Q. serrata (15 April to 10 May based on K. H., personal observation) and the monthly 
were less than 10, which confirmed that multicollinearity among these weather variables was

not a serious concern. We constructed GLMM models, which were a log link and negative

binomial error distribution, with the annual number of sound acorns (non-log-transformed) as

243 the response variable and each weather variable as the explanatory variable. The annual number

244 of female flowers was an offset variable, and the individual trees were treated as random factors.

245 We determined the best model, which describes the relationship between the survival rate of

246 female flowers and weather variables using the same method in the analyses of annual

247 variability in female flower number as mentioned above.

Relative contribution of each type of reproductive loss during the pre-dispersal phase

250 Key factor analysis (Podoler and Rogers 1975) was used to estimate the relative contribution

251 of factors that influenced plant reproductive potential to the observed variation in total pre-

252 dispersal losses. The reproductive losses due to factor $k_{i}$ and the total pre-dispersal loss $(K)$

253 were calculated for each year in each individual tree as follows:

$k_{i}=\log _{10}\left(N_{i-1}+1\right)-\log _{10}\left(N_{i}+1\right)$ 
$K=\sum_{i=1}^{n} k_{i}$

256 where $N_{i}$ is the number of female reproductive organs that remained after mortality due to

257 factor $i$ (the number per total area of $1.5 \mathrm{~m}^{2}$ per individual), and $n$ represents the number of

258 factors. We added 1 to those numbers before log-transformation to avoid excluding zero data.

259 The slope of the regression of $k_{i}$ on $K$ was used to determine the relative impact of each factor

260 on the total variation in the reduction of potential reproductive output (Jordano 1989, Traveset

261 1994, Fukumoto and Kajimura 2005, Hirayama et al. 2017): the higher regression value

262 contributes more to changes in the total mortality (Podoler and Rogers 1975). In this study, to

263 identify the slope of the regression between $k_{i}$ and $K$, we performed a LMM with each $k_{i}$ as

264 the response variable, $K$ as the explanatory variable, and the individual tree as a random factor.

organs suffered from each type of insect damage, as mentioned above, we determined the

267 seasonal order of factors damaging the organs as follows:

268 (1) damaged by cynipid wasps

269 (2) sap suction by adult weevils, mainly by M. ursulus

270 (3) damaged by moth larvae 
271 (4) oviposition by weevils other than M. ursulus, mainly by K. rectirostris

272 (5) oviposition by M. ursulus

273 Damage caused by other insects and vertebrate predation was assumed to be lower in order than insect damage because it usually occurred when the acorns had reached maturity. Meanwhile, reproductive loss due to abortion of pistillate flowers and immature acorns was assumed to

276 occur before insect damage in the analysis.

\section{Annual variability in the numbers of female flowers and sound acorns}

The annual numbers of sound acorns exhibited higher inter-year variation than those of female

284 intervals using the bootstrap method (Table 1). The annual number of sound acorns was 
production of female flowers in a year. Synchrony was stronger in the production of sound acorns $(0.68)$ than that of female flowers $(0.32)$, although average pairwise correlations in both

production of female flowers or sound acorns on their production in the following year (Online

Resource 3 and 4).

Relationships between weather variables and the annual production of female flowers and

300 For the annual number of female flowers per individual, in the models selected based on AIC 
the precipitation in May in one year before flowering, the change in average May temperature

304 from two years before flowering to one year before flowering, the average temperature in April

305 the year before flowering, the average temperature in April in the flowering year (Online

306 Resource 6). Among them, $\Delta \operatorname{AprT}\left(t_{i}\right)$, which was positively related to the annual number of

307 female flowers, was selected as the best model for predicting their production (Online Resource

$308 \quad 7$ and Table 2).

For the survival rate from female flowers to sound acorns per individual, in the models 
Except in 2014 and 2020, when the production of sound acorns was high for all individuals, the number of female organs tended to be greatly reduced by sap suction by adult weevils (Fig. 4, stage 3-4) and by oviposition by M. ursulus for all individuals (stage 6-7). Reproductive losses due to abortion of pistillate flowers and immature acorns (stage 1-2) and oviposition by weevils other than $M$. ursulus, mainly by $K$. rectirostris (stage 5-6), were not significantly related to total pre-dispersal loss, while reproductive losses due to almost all types of insect damage were significantly related to the total pre-dispersal loss (Table 3). Among the types of insect damage, the slope of the regression on the total pre-dispersal loss was the highest in oviposition by $M$. ursulus, followed by sap suction by adult weevils, mainly by M. ursulus (Table 3 and Online Resource 10).

\section{Discussion}

Although the annual production of female flowers per $Q$. serrata individual significantly

331 influenced the annual production of sound acorns (Fig. 2), the annual fluctuation of female 
by weather conditions during floral initiation and development and their internal resource

correlated with flowering intensity in the following year for the masting species $F$. crenata, supporting the resource budget model, which assumes that the fluctuation of reproductive efforts could be induced by resource depletion after heavy flowering (Isagi et al. 1997, Satake and Iwasa 2000). However, for Q. serrata, the annual production of female flowers was not affected by both the annual production of female flowers and sound acorns in the previous year (Online Resource 4), indicating that internal resources were not important for their annual variability. On the other hand, their production was affected by the change in average April temperature from one year before flowering to the flowering year (Table 2). Because April is the period when pistil differentiation in female flowers occurs immediately before flowering

346 (Hashizume et al. 2003), the weak fluctuation of annual female flower production may be induced by a weather cue, as suggested by Kelly et al. (2013). acorn production, compared with those in female flower production (Fig. 1 and Table1), 
implying that synchronised floral or seed abortion until maturity would work in sound acorn

351 production patterns in Q. serrata. For most of the 1-yr Quercus species, which require one year

to develop acorns, their annual seed production has a relationship with spring temperatures

when pollination occurs (Koenig and Knops 2014): higher spring temperature results in higher

354 phenological synchrony during the flowering season, contributing to increased pollen

355 availability and fertilisation success (Koenig et al. 2015, Bogdziewicz et al. 2020). After

356 fertilisation, acorn development has been reported to be strongly affected by water stress during

357 the summer and/or by resource supply, resulting in in synchronous fluctuation in mature acorn

358 production (Espelta et al. 2008, Perez-Ramos et al. 2010). However, for Q. serrata, the survival

359 rate of female flowers was not positively related to spring temperature, nor negatively related

360 to summer precipitation (Online Resource 8). Moreover, reproductive loss due to abortion of

361 pistillate flowers and immature acorns, mainly caused by intrinsic factors (Jordano 1989,

362 Traveset 1994), was not correlated with the total pre-dispersal loss (Fig. 4, Table 3, and Online

363 Resource 10), and the annual production of sound acorns was not affected by either female

364 flowers or sound acorns in the previous year (Online Resource 3). The annual variability in total

365 pre-dispersal loss was significantly influenced by almost all types of insect damage. Therefore, 
synchronised floral or seed abortion until maturity in $Q$. serrata is not caused by plant internal

mechanisms, such as pollination failure nor resource limitation, but by insect damage.

suction by M. ursulus, was the largest and most important factor that contributed to the annual

H. personal observation). They sucked sap from immature acorns using their proboscis immediately after emerging, and oviposited eggs in each acorn (one egg per acorn) from midwas strongly predicted by the average temperature in June (Table 2), which corresponds to the emergence of adult $M$. ursulus. The higher temperature in June probably enhanced the emergence of M. ursulus adults earlier, resulting in a phenological mismatch between their sap suction behaviour and acorn growth in Q. serrata; however, further long-term studies are required to clarify this mechanism. 
starvation at the individual level (Fig. 3 and Online Resource 5). Although predator satiation

may occur when the amount of annual female flower production exceeded a certain threshold,

predation rates were often high even at the high amount of the flower production (Fig. 3 and

Online Resource 5). Selection for predator satiation and starvation depends on various factors

of seed predators' characteristics, including the size, mobility, abundance, lifespan, and degree

of specialisation (Koenig et al. 2003, Bogdziewicz et al. 2021). For species with specialist seed

predators, it has been reported that high fluctuations in flowering intensity contribute to

main seed predator of $Q$. serrata, M. ursulus, is a generalist weevil that predates on various

et al. 2017, Hirayama et al. 2019); however, they prefer oak species with scale-like cupules,

such as Q. serrata (Hirayama et al. 2017). Ims (1990) predicted that the mechanisms that

promote within-group reproductive synchrony are unlikely to have evolved when predators 
generalist seed predator. The result of this study suggests that insect predation during the pre-

399 dispersal stage can proximately induce highly variable and synchronous sound seed production

400 for plant populations, which main seed predator is a generalist.

\section{Author Contributions}

$\mathrm{KH}$ conceived the ideas and designed methodology; $\mathrm{CH}, \mathrm{MY}, \mathrm{MT}$ and $\mathrm{KM}$ collected the data;

$\mathrm{KH}$ analyzed the data and wrote the manuscript. All authors contributed the drafts and gave

final approval for publication.

409 Barton K (2020) Mu-MIn: Multi-model inference. https://cran.rproject.org/web/packages/MuMIn/index.html. 
Bogdziewicz M, Pesendorfer M, Crone EE, Perez-Izquierdo C, Bonal R (2020) Flowering synchrony drives reproductive success in a wind-pollinated tree. Ecol. Lett. 23:18201826. https://doi.org/10.1111/ele.13609

Bogdziewicz M et al. (2021) Seed predation selects for reproductive variability and synchrony in perennial plants. New Phytol. 229:2357-2364. https://doi.org/10.1111/nph.16835

Burnham KP, Anderson DR (2002) Model selection and multimodel inference: a practical information-theoretic approach, 2nd edn. Springer, New York, NY USA

Crone EE, Lesica P (2006) Pollen and water limitation in Astragalus scaphoides, a plant that flowers in alternate years. Oecologia 150:40-49. https://doi.org/10.1007/s00442-0060506-0

Crone EE, Rapp JM (2014) Resource depletion, pollen coupling, and the ecology of mast seeding. Ann. N. Y. Acad. Sci. 1322:21-34. https://doi.org/10.1111/nyas. 12465

Espelta JM, Cortes P, Molowny-Horas R, Sanchez-Humanes B, Retana J (2008) Masting mediated by summer drought reduces acorn predation in Mediterranean oak forests. Ecology 89:805-817. https://doi.org/10.1890/07-0217.1 
430

Fukumoto H, Kajimura H (2001) Guild structures of seed insects in relation to acorn

development in two oak species. Ecol. Res. 16:145-155.

https://doi.org/10.1111/j.1440-1703.2001.00380.pp.x

Fukumoto H, Kajimura H (2005) Cumulative effects of mortality factors on reproductive output in two co-occurring Quercus species: which mortality factors most strongly reduce reproductive potential? Can. J. Bot. 83:1151-1158. https://doi.org/10.1139/b05090

Geological Survey of Japan AIST (2015) Seamless digital geological map of Japan 1:200,000. May 29, 2015 version.

Hashizume H, Taniguchi S, Lee JH (2003) Initiation and development of flower buds in Quercus serrata Thunb. Appl. For. Sci. 12:29-33.

Hirayama D, Okada M, Nanami S, Itoh A (2019) Correlation between the shoot-cutting behavior of the acorn weevil and the reproductive traits of host fagaceous trees. Plant Species Biol. 34:184-191. https://doi.org/10.1111/1442-1984.12246

Hirayama K, Imai T, Enomoto K, Tachikawa C (2017) Annual variability in acorn production and pre-dispersal damage to acorns of four fagaceous species in two adjacent forest 
stands with different mixed ratios in western Japan. Popul. Ecol. 59:343-354. https://doi.org/10.1007/s10144-017-0595-0

Imai T, Hirayama K (2013) Oviposition characteristics of Mechoris ursulus Roelofs on acorns https://doi.org/10.1016/0169-5347(94)90310-7

Jordano P (1989) Pre-dispersal biology of Pistacia lentiscus (Anacardiaceae): cumulative

Isagi Y, Sugimura K, Sumida A, Ito H (1997) How does masting happen and synchronize? J.

Iwatsuki K, Boufford DE, Ohba H (2006) Flora of Japan, Vol. IIa. Kodansha, Tokyo

Kelly D (1994) The evolutionary ecology of mast seeding. Trends Ecol. Evol. 9:465-470. insensitive to climate change. Ecol. Lett. 16:90-98. https://doi.org/10.1111/ele.12020 
462

463

464

465

466

467

468

469

470

471

472

473

474

475

Kelly D, Sork VL (2002) Mast seeding in perennial plants: why, how, where? Annu. Rev.

Ecol. Syst. 33:427-447. https://doi.org/10.1146/annurev.ecolsys.33.020602.095433

Kelly D, Sullivan JJ (1997) Quantifying the benefits of mast seeding on predator satiation and wind pollination in Chionochloa pallens (Poaceae). Oikos 78:143-150. https://doi.org/10.2307/3545810

Koenig WD et al. (2003) Dissecting components of population-level variation in seed production and the evolution of masting behavior. Oikos 102:581-591. https://doi.org/10.1034/j.1600-0706.2003.12272.x

Koenig WD, Knops JM, Carmen WJ, Pearse IS (2015) What drives masting? The phenological synchrony hypothesis. Ecology 96:184-192. https://doi.org/10.1890/140819.1

Koenig WD, Knops JMH (2014) Environmental correlates of acorn production by four species of Minnesota oaks. Popul. Ecol. 56:63-71. https://doi.org/10.1007/s10144-0130408-z 
Kon H, Noda T, Terazawa K, Koyama H, Yasaka M (2005) Evolutionary advantages of mast seeding in Fagus crenata. J. Ecol. 93:1148-1155. https://doi.org/10.1111/j.13652745.2005.01040.x

Matsuda K (1982) Studies on the early phase of the regeneration of Konara oak (Quercus serrata Thunb.) secondary forest I. Development and premature abscissions of Konara oak acorns. Japanese J. Ecol. 32:293-302. https://doi.org/10.18960/seitai.32.3_293

Miyazaki Y et al. (2014) Nitrogen as a key regulator of flowering in Fagus crenata: understanding the physiological mechanism of masting by gene expression analysis. Ecol. Lett. 17:1299-1309. https://doi.org/10.1111/ele.12338

Montesinos D, García-Fayos P, Verdú M (2012) Masting uncoupling: mast seeding does not follow all mast flowering episodes in a dioecious juniper tree. Oikos 121:1725-1736. https://doi.org/10.1111/j.1600-0706.2011.20399.x

Moreira X et al. (2019) Weather cues associated with masting behavior dampen the negative autocorrelation between past and current reproduction in oaks. Am. J. Bot. 106:51-60. https://doi.org/10.1002/ajb2.1210 
Norton DA, Kelly D (1988) Mast seeding over 33 years by Dacrydium cupressinum Lamb.

(rimu) (Podocarpaceae) in New Zealand: the importance of economies of scale. Funct.

Ecol. 2:399-408. https://doi.org/10.2307/2389413

Pearse IS, Koenig WD, Kelly D (2016) Mechanisms of mast seeding: resources, weather, cues, and selection. New Phytol. 212:546-562. https://doi.org/10.1111/nph.14114

Perez-Ramos IM, Ourcival JM, Limousin JM, Rambal S (2010) Mast seeding under increasing drought: results from a long-term data set and from a rainfall exclusion experiment. Ecology 91:3057-3068. https://doi.org/10.1890/09-2313.1

Pesendorfer MB, Koenig WD, Pearse IS, Knops JMH, Funk KA, Whitney K (2016) Individual resource limitation combined with population-wide pollen availability drives masting in the valley oak (Quercus lobata). J. Ecol. 104:637-645. https://doi.org/10.1111/1365-2745.12554

Podoler H, Rogers D (1975) A new method for the identification of key factors from life-table data. J. Anim. Ecol. 44:85-114. https://doi.org/10.2307/3853

Quinn GP, Keough MJ (2002) Experimental design and data analysis for biologists. Cambridge University Press, Cambridge 
R Core Team (2021) R: A language and environment for statistical computing. R foundation for statistical computing. https://www.R-project.org/.

Satake A, Iwasa Y (2000) Pollen coupling of forest trees: forming synchronized and periodic reproduction out of chaos. J. Theor. Biol. 203:63-84. https://doi.org/10.1006/jtbi.1999.1066

Schermer E et al. (2019) Pollen limitation as a main driver of fruiting dynamics in oak populations. Ecol. Lett. 22:98-107. https://doi.org/10.1111/ele.13171

Shibata M et al. (2002) Synchronized annual seed production by 16 principal tree species in a temperate deciduous forest, Japan. Ecology 83:1727-1742. https://doi.org/10.2307/3071991

Soil Survey Staff (2010) Keys to soil taxonomy, 11th edn. Natural Resource Conservation

Sork VL, Bramble J, Sexton O (1993) Ecology of mast-fruiting in three species of north American deciduous oaks. Ecology 74:528-541. https://doi.org/10.2307/1939313 
523 Xiao Z et al. (2017) Seed-predator satiation and Janzen-Connell effects vary with spatial scales for seed-feeding insects. Ann. Bot. 119:109-116.

525 https://doi.org/10.1093/aob/mcw224

526 
Table 1 Mean individual variability $\left(\overline{C V_{l}}\right)$ and mean synchrony between trees $\left(\overline{r_{p}}\right)$ in the annual number of female flowers and sound acorns of Q. serrata.

\begin{tabular}{lll}
\hline & Female flowers & Sound acorns \\
\hline$\overline{C V_{l}}$ & $0.50(0.36-0.58)$ & $1.51(1.02-1.72)$ \\
& $0.32(-0.16-0.27)$ & $0.68(-0.16-0.24)$ \\
\hline$r_{p}$ & & \\
\hline
\end{tabular}

Numbers in parentheses indicate $95 \%$ confidence intervals using the bootstrap method. 
Table 2 The best model predicting the annual number of female flowers and survival rate from

female flowers to sound acorns from the weather variables using a GLMM.

\begin{tabular}{lllll}
\hline & Estimate & SE & $z$-Value & $P$ \\
\hline The number of female flowers & & & & \\
(Intercept) & 6.599 & 0.142 & 46.46 & $<0.001$ \\
Changes in average temperature in 0.222 & 0.073 & 3.06 & 0.002 \\
April from one year before & & & & \\
flowering to the flowering year & & & & \\
\end{tabular}

The survival rate from female flowers to sound acorns

$\begin{array}{lllll}\text { (Intercept) } & -41.410 & 4.881 & -8.57 & <0.001 \\ \text { average temperature in June } & 1.741 & 0.222 & 7.85 & <0.001\end{array}$


Table 3 The results of LMMs test indicating the regression of each reproductive loss due to main factors on the total pre-dispersal loss $(K)$.

\begin{tabular}{ccccc}
\hline & Estimate & SE & $t$-Value & $P$ \\
\hline Abortion of female flowers and immature acorns & & & & \\
(Intercept) & 0.361 & 0.060 & 6.029 & $<0.001$ \\
Total $K$ & -0.019 & 0.025 & -0.783 & 0.439 \\
\hline Damaged by cynipid wasps & & & & \\
(Intercept) & -0.015 & 0.013 & -1.135 & 0.268 \\
Total $K$ & 0.026 & 0.006 & 4.427 & $<0.001$ \\
\hline
\end{tabular}

Sap suction by adult weevils, mainly by $M$. ursulus

$\begin{array}{lllll}\text { (Intercept) } & -0.010 & 0.100 & -0.103 & 0.919 \\ \text { Total } K & 0.274 & 0.050 & 5.445 & <0.001\end{array}$

Damaged by moth larvae

$\begin{array}{lllll}\text { (Intercept) } & -0.041 & 0.039 & -1.077 & 0.288 \\ \text { Total } K & 0.108 & 0.020 & 5.336 & <0.001\end{array}$

Oviposition by weevils other than M. ursulus, mainly by $K$. rectirostris

$\begin{array}{lllll}\text { (Intercept) } & 0.036 & 0.032 & 1.112 & 0.273 \\ \text { Total } K & 0.030 & 0.017 & 1.755 & 0.087\end{array}$

Oviposition by M. ursulus

$\begin{array}{lllll}\text { (Intercept) } & -0.199 & 0.118 & -1.680 & 0.101 \\ \text { Total } K & 0.448 & 0.062 & 7.218 & <0.001\end{array}$




\section{Figure legends}

Fig. 1 Annual variability in the number of (a) female flowers and (b) sound acorns for each individual tree.

Fig. 2 The relationship between the annual number of female flowers and sound acorns for each

individual tree over seven years. Different letters indicate different individuals. The regression line is a predicted relationships based upon the result of the GLMM $(P<0.05)$ testing the effects

of the number of female flowers per year $\left(t_{i}\right)$ on the number of sound acorns per year $\left(t_{i}\right)$. Individual trees were treated as a random factor.

Fig. 3 The relationship of the proportion of the female organs damaged by insects during one year to (a) the annual number of female flowers and (b) the ratio of the number of female flowers in the current year to that in the previous year for each individual. Different letters indicate different individuals. When the number of flowers was zero, the data were excluded. The regression line is a predicted relationships based upon the result of the GLMM $(P<0.05)$ 
testing the effects of the annual number of female flowers per year $\left(t_{i}\right)$ on the proportion of the organs damaged by insects during a year $\left(t_{i}\right)$. Individual trees were treated as a random factor.

Fig. 4 Reduction in the number of female reproductive organs for each individual throughout the successive stages for each observed year. Stage 1, female flowers (i.e., initial number of the organs); stage 2, organs remaining after abortion in the immature stage; stage 3 , organs remaining after being damaged by cynipid wasps; stage 4 , organs remaining after being attacked through sap suction by adult weevils; stage 5 , organs remaining after being damaged by moth larvae; stage 6, organs remaining after oviposited by weevils other than Mechoris ursulus; stage 7, organs remaining after oviposited by M. ursulus; stage 8, organs remaining after other damage mainly due to animals (i.e., number of sound acorns). 


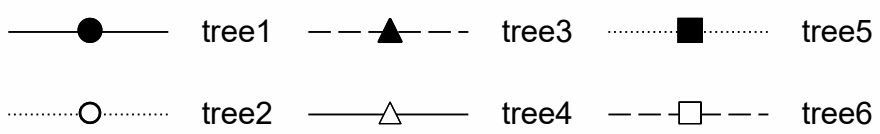

(a) Female flowers

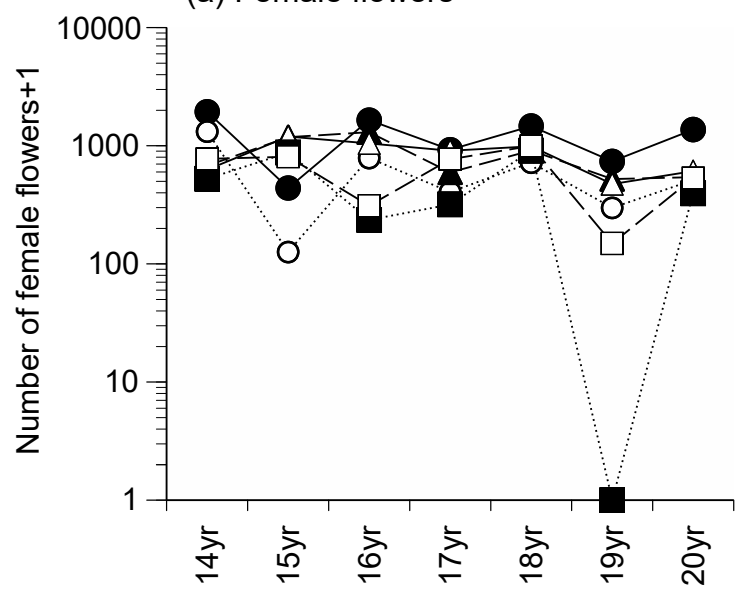

(b) Sound acorns

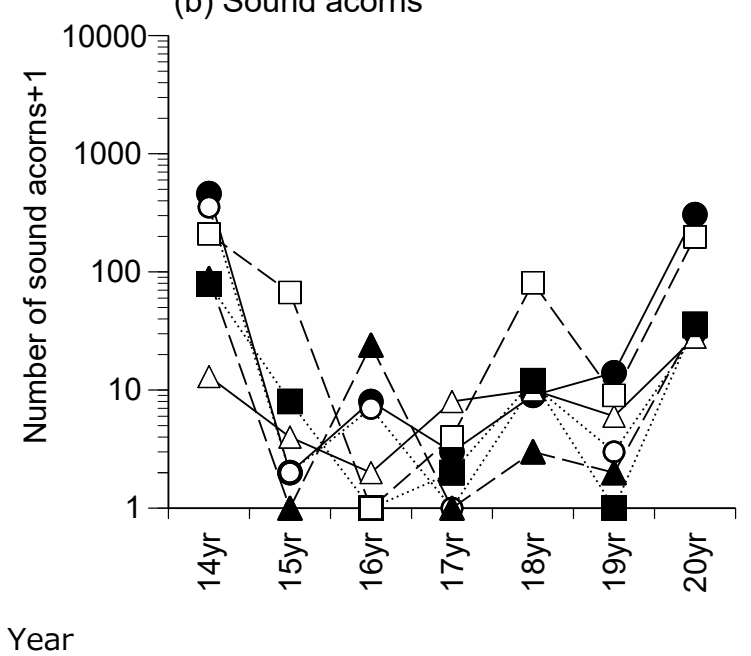

Fig. 1 
- tree1 $\Delta$ tree3 - tree5

$\circ$ tree2 $\Delta$ tree4 $\square$ tree6

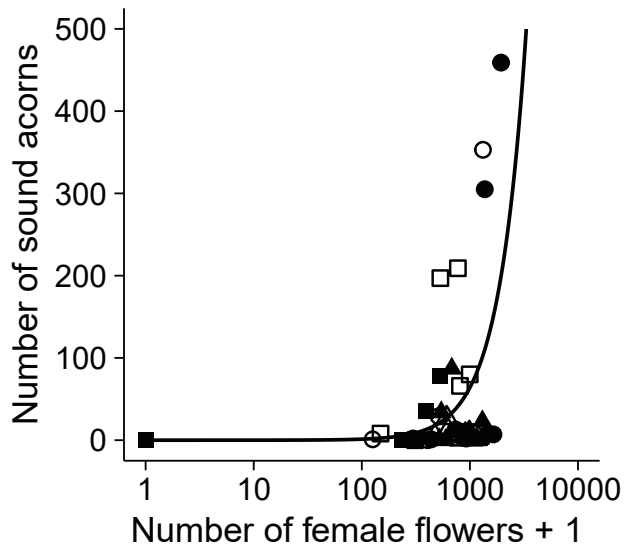

Fig. 2 
(a)

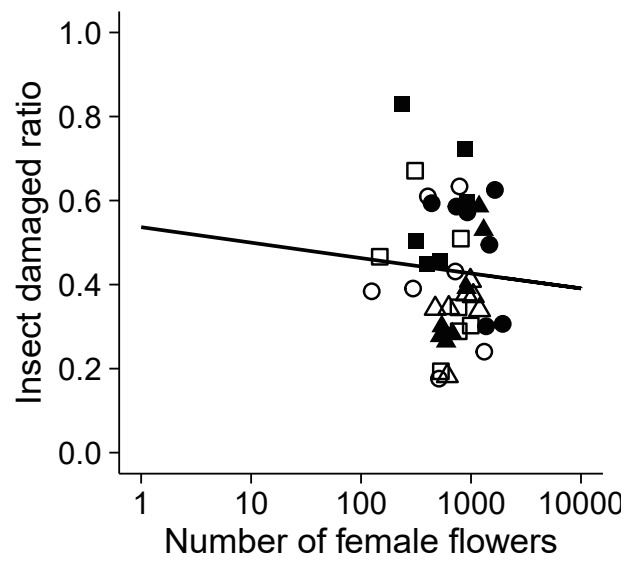

- tree1 $\Delta$ tree3 $\square$ tree5

$\circ$ tree2 $\Delta$ tree4 $\square$ tree6

(b)

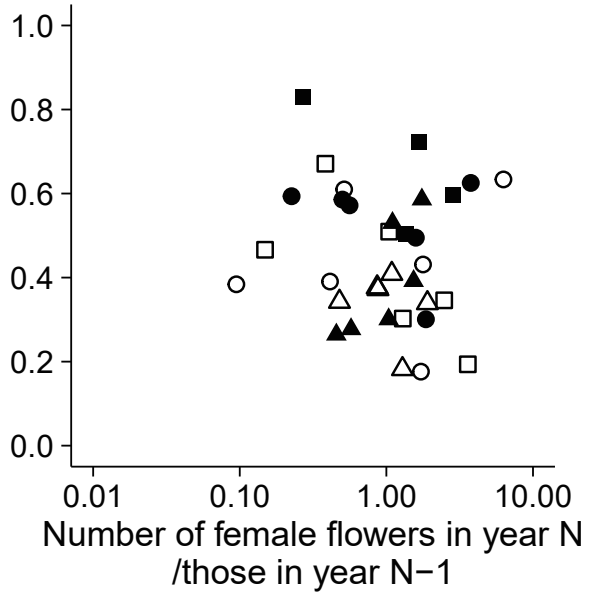

Fig. 3 


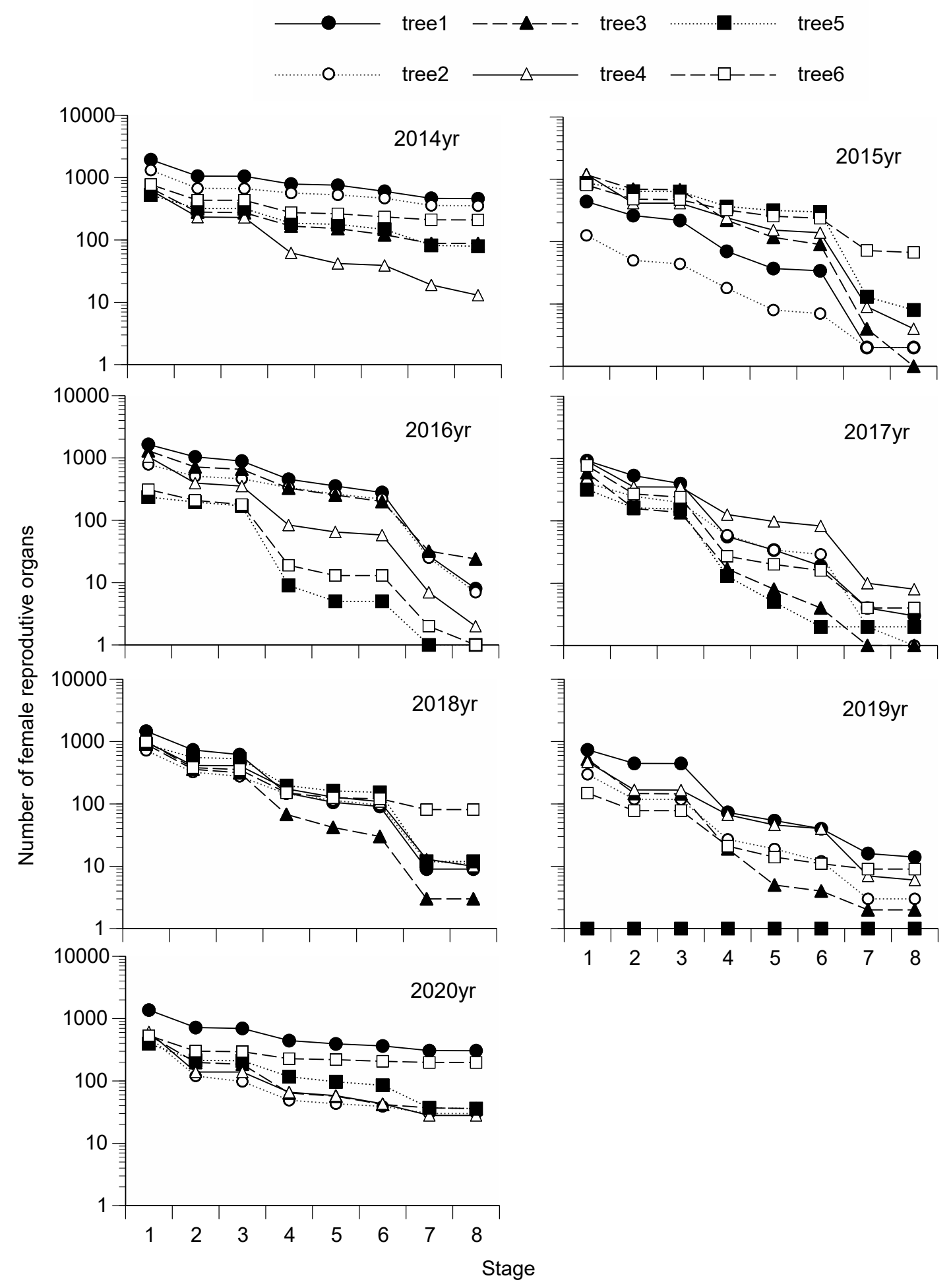

Fig. 4 


\section{Supplementary Information}

\section{Annual variability in sound acorn production was regulated by a generalist seed predator weevil in Quercus serrata}

Kimiko Hirayama ${ }^{1 *}$, Kenta Mizo ${ }^{1}$, Manaka Tatsuno ${ }^{2}$, Mizuki Yoshikawa ${ }^{2}$, Chieri Tachikawa ${ }^{2}$

${ }^{1}$ Graduate School of Life and Environmental Sciences, Kyoto Prefectural University,

Hangi-cho 1-5, Shimogamo, Sakyo-ku, Kyoto, Japan

${ }^{2}$ Faculty of Life and Environmental Sciences, Kyoto Prefectural University,

Hangi-cho 1-5, Shimogamo, Sakyo-ku, Kyoto, Japan

*Corresponding author: Kimiko Hirayama

Email: khirayam@gmail.com 
Online resource 1 Data of weather variables which were analysed in relation to the production of female flowers.

\begin{tabular}{|c|c|c|c|c|c|c|c|c|}
\hline & & \multicolumn{7}{|c|}{ Flowering year $\left(t_{i}\right)$} \\
\hline & & 2014 & 2015 & 2016 & 2017 & 2018 & 2019 & 2020 \\
\hline $\operatorname{AprT}\left(t_{i-1}\right)$ & average Apr. temp. in year $\left(t_{i-1}\right)$ & 12.1 & 12.3 & 13.5 & 14.2 & 12.8 & 14.5 & 11.8 \\
\hline $\begin{array}{l}\Delta \text { AprT } \\
\left(t_{i-1}\right)\end{array}$ & $\begin{array}{l}\text { change in average Apr. temp. } \\
\text { from year }\left(t_{i-2}\right) \text { to year }\left(t_{i-1}\right)^{*} 1\end{array}$ & -0.7 & 0.2 & 1.1 & 0.7 & -1.3 & 1.7 & -2.6 \\
\hline $\operatorname{AprP}\left(t_{i-1}\right)$ & Apr. precipitation in year $\left(t_{i-1}\right) * 2$ & 111.5 & 85.0 & 170.0 & 163.0 & 149.5 & 157.0 & 102.5 \\
\hline $\begin{array}{l}\Delta \text { AprP } \\
\left(t_{i-1}\right)\end{array}$ & $\begin{array}{l}\text { change in Apr. precipitation from } \\
\text { year }\left(t_{i-2}\right) \text { to year }\left(t_{i-1}\right) * 3\end{array}$ & -23.0 & -26.5 & 85.0 & -7.0 & -13.5 & 7.5 & -54.5 \\
\hline $\begin{array}{l}\text { MayT } \\
\left(t_{i-1}\right)\end{array}$ & average May temp. in year $\left(t_{i-1}\right)$ & 18.2 & 17.7 & 19.1 & 18.9 & 19.0 & 18.0 & 18.5 \\
\hline $\begin{array}{l}\Delta \text { MayT } \\
\left(t_{i-1}\right)\end{array}$ & $\begin{array}{l}\text { change in average May temp. } \\
\text { from year }\left(t_{i-2}\right) \text { to year }\left(t_{i-1}\right)\end{array}$ & 0.9 & -0.5 & 1.4 & -0.2 & 0.1 & -1.0 & 0.5 \\
\hline $\operatorname{MayP}\left(t_{i-1}\right)$ & May precipitation in year $\left(t_{i-1}\right)$ & 52.0 & 78.5 & 133.0 & 144.0 & 74.0 & 214.0 & 87.5 \\
\hline $\begin{array}{l}\Delta \text { MayP } \\
\left(t_{i-1}\right)\end{array}$ & $\begin{array}{l}\text { change in May precipitation from } \\
\text { year }\left(t_{i-2}\right) \text { to year }\left(t_{i-1}\right)^{* 1}\end{array}$ & -6.0 & 26.5 & 54.5 & 11.0 & -70.0 & 140.0 & -126.5 \\
\hline $\operatorname{JunT}\left(t_{i-1}\right)$ & average June temp. in year $\left(t_{i-1}\right)$ & 23.7 & 22.4 & 20.9 & 21.5 & 20.3 & 21.5 & 21.8 \\
\hline $\begin{array}{l}\Delta \mathrm{JunT} \\
\left(t_{i-1}\right)\end{array}$ & $\begin{array}{l}\text { change in average June temp. } \\
\text { from year }\left(t_{i-2}\right) \text { to year }\left(t_{i-1}\right)\end{array}$ & 2.3 & -1.2 & -1.6 & 0.6 & -1.1 & 1.2 & 0.3 \\
\hline $\operatorname{JunP}\left(t_{i-1}\right)$ & June precipitation in year $\left(t_{i-1}\right) * 2$ & 169.0 & 64.5 & 281.5 & 261.5 & 205.0 & 251.0 & 140.5 \\
\hline $\begin{array}{l}\Delta \mathrm{JunP} \\
\left(t_{i-1}\right)\end{array}$ & $\begin{array}{l}\text { change in June precipitation from } \\
\text { year }\left(t_{i-2}\right) \text { to year }\left(t_{i-1}\right)^{*} 3\end{array}$ & -117.0 & -104.5 & 217.0 & -20.0 & -56.5 & 46.0 & -110.5 \\
\hline
\end{tabular}




\begin{tabular}{|c|c|c|c|c|c|c|c|c|}
\hline $\operatorname{JulT}\left(t_{i-1}\right)$ & average July temp. in year $\left(t_{i-1}\right)$ & 28.1 & 25.8 & 25.6 & 26.1 & 26.9 & 27.9 & 25.0 \\
\hline$\Delta \operatorname{JulT}\left(t_{i-1}\right)$ & $\begin{array}{l}\text { change in average July temp. } \\
\text { from year }\left(t_{i-2}\right) \text { to year }\left(t_{i-1}\right)\end{array}$ & 1.7 & -2.3 & -0.2 & 0.5 & 0.8 & 1.0 & -2.9 \\
\hline $\operatorname{JulP}\left(t_{i-1}\right)$ & July precipitation in year $\left(t_{i-1}\right)$ & 156.5 & 129.5 & 447.5 & 113.0 & 243.0 & 487.0 & 253.0 \\
\hline$\Delta \operatorname{JulP}\left(t_{i-1}\right)$ & $\begin{array}{l}\text { change in July precipitation from } \\
\text { year }\left(t_{i-2}\right) \text { to year }\left(t_{i-1}\right)\end{array}$ & -262.0 & -27.0 & 318.0 & -334.5 & 130.0 & 244.0 & -234.0 \\
\hline $\operatorname{AugT}\left(t_{i-1}\right)$ & average Aug. temp. in year $\left(t_{i-1}\right)$ & 28.6 & 26.0 & 26.6 & 27.3 & 26.9 & 27.6 & 27.7 \\
\hline $\begin{array}{l}\Delta \operatorname{AugT} \\
\left(t_{i-1}\right)\end{array}$ & $\begin{array}{l}\text { change in average Aug. temp. } \\
\text { from year }\left(t_{i-2}\right) \text { to year }\left(t_{i-1}\right)\end{array}$ & 0.8 & -2.6 & 0.6 & 0.7 & -0.4 & 0.6 & 0.1 \\
\hline $\operatorname{AugP}\left(t_{i-1}\right)$ & Aug. precipitation in year $\left(t_{i-1}\right)$ & 102.5 & 458.0 & 209.0 & 126.0 & 139.0 & 127.0 & 373.5 \\
\hline $\begin{array}{l}\Delta \text { AugP } \\
\left(t_{i-1}\right)\end{array}$ & $\begin{array}{l}\text { change in Aug. precipitation from } \\
\text { year }\left(t_{i-2}\right) \text { to year }\left(t_{i-1}\right)\end{array}$ & -46.5 & 355.5 & $\begin{array}{l}- \\
249.0\end{array}$ & -83.0 & 13.0 & -12.0 & 246.5 \\
\hline $\operatorname{SepT}\left(t_{i-1}\right)$ & average Sep. temp. in year $\left(t_{i-1}\right)$ & 24.1 & 21.4 & 21.3 & 23.7 & 21.5 & 21.9 & 24.5 \\
\hline $\begin{array}{l}\Delta \mathrm{SepT} \\
\left(t_{i-1}\right)\end{array}$ & $\begin{array}{l}\text { change in average Sep. temp. } \\
\text { from year }\left(t_{i-2}\right) \text { to year }\left(t_{i-1}\right)\end{array}$ & -0.9 & -2.7 & -0.1 & 2.5 & -2.2 & 0.4 & 2.6 \\
\hline $\operatorname{SepP}\left(t_{i-1}\right)$ & Sep. precipitation in year $\left(t_{i-1}\right)$ & 406.0 & 112.5 & 192.0 & 383.0 & 173.0 & 401.0 & 77.5 \\
\hline $\begin{array}{l}\Delta \text { SepP } \\
\left(t_{i-1}\right)\end{array}$ & $\begin{array}{l}\text { change in Sep. precipitation from } \\
\text { year }\left(t_{i-2}\right) \text { to year }\left(t_{i-1}\right)\end{array}$ & 272.0 & -293.5 & 79.5 & 191.0 & $\begin{array}{l}- \\
210.0\end{array}$ & 228.0 & -323.5 \\
\hline $\operatorname{MarT}\left(t_{i}\right)$ & average Mar. temp. in year $\left(t_{i}\right)$ & 7.1 & 7.5 & 8.1 & 6.2 & 9.1 & 7.4 & 8.6 \\
\hline$\Delta \operatorname{MarT}\left(t_{i}\right)$ & $\begin{array}{l}\text { change in average Mar. temp. } \\
\text { from year }\left(t_{i-1}\right) \text { to year }\left(t_{i}\right)\end{array}$ & -1.3 & 0.5 & 0.5 & -1.9 & 2.9 & -1.6 & 1.2 \\
\hline $\operatorname{MarP}\left(t_{i}\right)$ & Mar. precipitation in year $\left(t_{i}\right)$ & 167.0 & 158.0 & 62.5 & 68.5 & 143.5 & 77.5 & 99.0 \\
\hline$\Delta \operatorname{MarP}\left(t_{i}\right)$ & change in Mar. precipitation from & 100.5 & -9.0 & -95.5 & 6.0 & 75.0 & -66.0 & 21.5 \\
\hline
\end{tabular}




\begin{tabular}{|c|c|c|c|c|c|c|c|c|}
\hline & year $\left(t_{i-1}\right)$ to year $\left(t_{i}\right)$ & & & & & & & \\
\hline $\operatorname{AprT}\left(t_{i}\right)$ & average Apr. temp. in year $\left(t_{i}\right)$ & 12.3 & 13.5 & 14.2 & 12.8 & 14.5 & 11.8 & 11.0 \\
\hline$\Delta \mathrm{AprT}\left(t_{i}\right)$ & $\begin{array}{l}\text { change in average Apr. temp. } \\
\text { from year }\left(t_{i-1}\right) \text { to year }\left(t_{i}\right)\end{array}$ & 0.2 & 1.1 & 0.7 & -1.3 & 1.7 & -2.6 & -0.8 \\
\hline $\operatorname{AprP}\left(t_{i}\right)$ & Apr. precipitation in year $\left(t_{i}\right)$ & 85.0 & 170.0 & 163.0 & 149.5 & 157.0 & 102.5 & 126.0 \\
\hline$\Delta \operatorname{AprP}\left(t_{i}\right)$ & $\begin{array}{l}\text { change in Apr. precipitation from } \\
\text { year }\left(t_{i-1}\right) \text { to year }\left(t_{i}\right)\end{array}$ & -26.5 & 85.0 & -7.0 & -13.5 & 7.5 & -54.5 & 23.5 \\
\hline
\end{tabular}

Temperature is in ${ }^{\circ} \mathrm{C}$; precipitation is in mm. Variables marked $* 1, * 2$, and $* 3$ were highly correlated with each other and had been found to have a high VIF value $(>10)$. We adopted one variable from each pair. 
Online Resource 2 Data of weather variables which were analysed in relation to survival rate from female flowers to sound acorns.

\begin{tabular}{|c|c|c|c|c|c|c|c|c|}
\hline & & \multicolumn{7}{|c|}{ Flowering and acorn maturing year $\left(t_{i}\right)$} \\
\hline & & 2014 & 2015 & 2016 & 2017 & 2018 & 2019 & 2020 \\
\hline $\begin{array}{l}\text { Apr15T } \\
\left(t_{i}\right)\end{array}$ & $\begin{array}{l}\text { Average temp. from } 15 \text { th Apr. to } \\
\text { 10th May in year }\left(t_{i}\right)\end{array}$ & 14.6 & 16.3 & 15.5 & 15.4 & 15.7 & 14.8 & 14.3 \\
\hline $\operatorname{Apr} 15 \mathrm{P}\left(t_{i}\right)$ & $\begin{array}{l}\text { Precipitation from } 15 \text { th Apr. to } \\
\text { 10th May in year }\left(t_{i}\right)\end{array}$ & 82.5 & 67.5 & 106.5 & 102.0 & 206.5 & 59.5 & 72.5 \\
\hline $\operatorname{AprT}\left(t_{i}\right)$ & Average Apr. temp in year $\left(t_{i}\right)$ & 12.3 & 13.5 & 14.2 & 12.8 & 14.5 & 11.8 & 11.0 \\
\hline $\operatorname{AprP}\left(t_{i}\right)$ & Apr. precipitation in year $\left(t_{i}\right)$ & 85.0 & 170.0 & 163.0 & 149.5 & 157.0 & 102.5 & 126.0 \\
\hline $\operatorname{MayT}\left(t_{i}\right)$ & Average May temp in year $\left(t_{i}\right)$ & 17.7 & 19.1 & 18.9 & 19.0 & 18.0 & 18.5 & 18.5 \\
\hline $\operatorname{MayP}\left(t_{i}\right)$ & May precipitation in year $\left(t_{i}\right)$ & 78.5 & 133.0 & 144.0 & 74.0 & 214.0 & 87.5 & 116.5 \\
\hline $\operatorname{JunT}\left(t_{i}\right)$ & Average Jun. temp in year $\left(t_{i}\right)$ & 22.4 & 20.9 & 21.5 & 20.3 & 21.5 & 21.8 & 22.7 \\
\hline $\operatorname{JunP}\left(t_{i}\right)$ & Jun. precipitation in year $\left(t_{i}\right)$ & 64.5 & 281.5 & 261.5 & 205.0 & 251.0 & 140.5 & 271.0 \\
\hline $\operatorname{JulT}\left(t_{i}\right)$ & Average Jul. temp in year $\left(t_{i}\right)$ & 25.8 & 25.6 & 26.1 & 26.9 & 27.9 & 25.0 & 24.2 \\
\hline $\operatorname{JulP}\left(t_{i}\right)$ & Jul. precipitation in year $\left(t_{i}\right)$ & 129.5 & 447.5 & 113.0 & 243.0 & 487.0 & 253.0 & 636.0 \\
\hline $\operatorname{AugT}\left(t_{i}\right)$ & Average Aug. temp in year $\left(t_{i}\right)$ & 26.0 & 26.6 & 27.3 & 26.9 & 27.6 & 27.7 & 28.7 \\
\hline $\operatorname{AugP}\left(t_{i}\right)$ & Aug. precipitation in year $\left(t_{i}\right)$ & 458.0 & 209.0 & 126.0 & 139.0 & 127.0 & 373.5 & 17.5 \\
\hline $\operatorname{SepT}\left(t_{i}\right)$ & Average Sep. temp in year $\left(t_{i}\right)$ & 21.4 & 21.3 & 23.7 & 21.5 & 21.9 & 24.5 & 23.7 \\
\hline $\operatorname{SepP}\left(t_{i}\right)$ & Sep. precipitation in year $\left(t_{i}\right)$ & 112.5 & 192.0 & 383.0 & 173.0 & 401.0 & 77.5 & 131.0 \\
\hline
\end{tabular}

Temperature is in ${ }^{\circ} \mathrm{C}$; precipitation is in $\mathrm{mm}$. 
Online Resource 3 The results of GLMMs testing the effects of the number of female flowers per year $\left(t_{i}\right)$, in year $\left(t_{i-1}\right)$ and the number of sound acorns per year $\left(t_{i-1}\right)$, on the number of sound acorns per year $\left(t_{i}\right)$. Individual trees were treated as a random factor.

\begin{tabular}{|c|c|c|c|c|}
\hline & Estimate & SE & $z$-Value & $P$ \\
\hline (Intercept) & -7.66 & 3.11 & -2.46 & 0.014 \\
\hline $\log _{10}$ [the number of female flowers & 3.94 & 1.08 & 3.64 & $<0.001$ \\
\hline \multicolumn{5}{|l|}{ in year $\left.\left(t_{i}\right)+1\right]$} \\
\hline (Intercept) & 6.441 & 2.463 & 2.61 & 0.009 \\
\hline $\log _{10}$ [the number of female flowers & -1.325 & 0.891 & -1.49 & 0.137 \\
\hline \multicolumn{5}{|l|}{ in year $\left.\left(t_{i-1}\right)+1\right]$} \\
\hline (Intercept) & 3.352 & 0.619 & 5.41 & $<0.001$ \\
\hline $\log _{10}$ [the number of sound acorns & -0.474 & 0.558 & -0.85 & 0.40 \\
\hline
\end{tabular}


Online Resource 4 The results of GLMMs testing the effects of the number of female flowers per year $\left(t_{i-1}\right)$ and the number of sound acorns per year $\left(t_{i-1}\right)$ on the number of female flowers per year $\left(t_{i}\right)$. Individual trees were treated as a random factor.

\begin{tabular}{lllll}
\hline & Estimate & SE & $z$-Value & $P$ \\
\hline Intercept) & 6.176 & 0.699 & 8.83 & $<0.001$ \\
$\log _{10}[$ the number of female flowers & 0.147 & 0.250 & 0.59 & 0.56 \\
in year $\left.\left(t_{i-1}\right)+1\right]$ & & & & \\
\hline$($ Intercept $)$ & 6.757 & 0.202 & 33.53 & $<0.001$ \\
$\log _{10}[$ the number of sound acorns & -0.222 & 0.165 & -1.34 & 0.18 \\
in year $\left.\left(t_{i-1}\right)+1\right]$ & & & & \\
\hline
\end{tabular}


Online Resource 5 The results of GLMMs testing the effects of the annual number of female flowers per year $\left(t_{i}\right)$ and the ratio of the annual number of female flowers per year $\left(t_{i}\right)$ to the year before $\left(t_{i-1}\right)$ on the ratio of the organs damaged by insects during a year $\left(t_{i}\right)$. Individual trees were treated as a random factor.

\begin{tabular}{lllll}
\hline & Estimate & SE & $z$-Value & $P$ \\
\hline Intercept $)$ & -0.474 & 0.620 & -0.76 & 0.44 \\
$\log _{10}[$ the number of female flowers & -0.132 & 0.218 & -0.61 & 0.54 \\
in year $\left.\left(t_{i}\right)\right]$ & & & & \\
\hline Intercept $)$ & -0.800 & 0.085 & -9.42 & $<0.001$ \\
$\log _{10}[$ the number of female flowers & -0.099 & 0.142 & -0.70 & 0.49 \\
in year $\left(t_{i}\right) /$ year $\left.\left(t_{i-1}\right)\right]$ & & & &
\end{tabular}


Online Resource 6 Five explanatory variables selected based on lower AIC of GLMM models which tested the relationship between the annual female flowers and each of weather variables. Individual trees were treated as a random factor. See Online Resource 1 for an abbreviation of the weather parameters.

\begin{tabular}{|l|l|l|l|l|l|l|}
\hline & $($ Intercept $)$ & Estimate & SE & $z$-Value & $P$ & AIC \\
\hline$\Delta \operatorname{AprT}\left(t_{i}\right)$ & 6.599 & 0.222 & 0.073 & 3.064 & 0.002 & 632.7 \\
\hline $\operatorname{MayP}\left(t_{i-1}\right)$ & 7.224 & -0.006 & 0.002 & -2.925 & 0.003 & 633.5 \\
\hline$\Delta$ MayT $\left(t_{i-1}\right)$ & 6.555 & 0.269 & 0.147 & 1.837 & 0.066 & 637.2 \\
\hline $\operatorname{AprT}\left(t_{i-1}\right)$ & 9.366 & -0.213 & 0.119 & -1.783 & 0.075 & 637.5 \\
\hline $\operatorname{AprT}\left(t_{i}\right)$ & 4.650 & 0.151 & 0.088 & 1.712 & 0.087 & 637.7 \\
\hline
\end{tabular}

Temperature is in ${ }^{\circ} \mathrm{C}$; precipitation is in $\mathrm{mm}$. 
Online Resource 7 The top models extracted from the full model using the selected five explanatory variables are shown based on the results of AIC values. Numerical values indicated estimated values of the models. See Online Resource 1 for an abbreviation of the weather parameters.

\begin{tabular}{|l|l|l|l|l|l|l|}
\hline$($ Intercept $)$ & $\operatorname{AprT}\left(t_{i-1}\right)$ & $\Delta \operatorname{MayT}\left(t_{i-1}\right)$ & $\operatorname{MayP}\left(t_{i-1}\right)$ & $\operatorname{AprT}\left(t_{i}\right)$ & $\Delta \operatorname{AprT}\left(t_{i}\right)$ & AIC \\
\hline 6.599 & & & & & 0.222 & 632.7 \\
\hline 5.448 & & & -0.005 & 0.133 & & 633.0 \\
\hline 7.224 & & & -0.006 & & & 633.5 \\
\hline 6.909 & & & -0.003 & & 0.143 & 633.6 \\
\hline 3.776 & 0.308 & & -0.011 & & & 633.8 \\
\hline 6.568 & & 0.136 & & & 0.189 & 633.8 \\
\hline
\end{tabular}

Temperature is in ${ }^{\circ} \mathrm{C}$; precipitation is in $\mathrm{mm}$. 
Online Resource 8 Five explanatory variables selected based on lower AIC of GLMM models which tested the relationship between the survival rate from female flowers to sound acorns and each of weather variables. Individual trees were treated as a random factor. See Online Resource 2 for an abbreviation of the weather parameters.

\begin{tabular}{|l|l|l|l|l|l|l|}
\hline & $($ Intercept) & Estimate & SE & $z$-Value & $P$ & AIC \\
\hline $\operatorname{JunT}\left(t_{i}\right)$ & -41.407 & 1.741 & 0.222 & 7.850 & $<0.001$ & 323.9 \\
\hline $\operatorname{Apr} 15 \mathrm{~T}\left(t_{i}\right)$ & 20.998 & -1.609 & 0.292 & -5.511 & $<0.001$ & 338.9 \\
\hline $\operatorname{AprP}\left(t_{i}\right)$ & 1.512 & -0.037 & 0.007 & -4.954 & $<0.001$ & 339.2 \\
\hline $\operatorname{MayT}\left(t_{i}\right)$ & 34.766 & -2.063 & 0.519 & -3.979 & $<0.001$ & 344.7 \\
\hline $\operatorname{AprT}\left(t_{i}\right)$ & 6.761 & -0.783 & 0.192 & -4.075 & $<0.001$ & 346.4 \\
\hline
\end{tabular}

Temperature is in ${ }^{\circ} \mathrm{C}$; precipitation is in $\mathrm{mm}$. 
Online Resource 9 The top models extracted from the full model using the selected five explanatory variables are shown based on the results of AIC values. Numerical values indicated estimated values of the models. See Online Resource 2 for an abbreviation of the weather parameters.

\begin{tabular}{|l|l|l|l|l|l|l|}
\hline$($ Intercept) & Apr15T $\left(t_{i}\right)$ & $\operatorname{AprT}\left(t_{i}\right)$ & $\operatorname{AprP}\left(t_{i}\right)$ & $\operatorname{MayT}\left(t_{i}\right)$ & $\operatorname{JunT}\left(t_{i}\right)$ & AIC \\
\hline-22.960 & 1.397 & -0.758 & & -1.285 & 1.449 & 322.5 \\
\hline-41.410 & & & & & 1.741 & 323.9 \\
\hline-32.790 & & & -0.011 & & 1.409 & 323.9 \\
\hline-48.670 & 0.637 & & -0.016 & -0.517 & 1.727 & 324.4 \\
\hline-26.430 & & & & -0.517 & 1.488 & 324.5 \\
\hline-23.640 & 1.401 & -0.750 & -0.001 & -1.260 & 1,455 & 324.5 \\
\hline
\end{tabular}

Temperature is in ${ }^{\circ} \mathrm{C}$; precipitation is in $\mathrm{mm}$. 


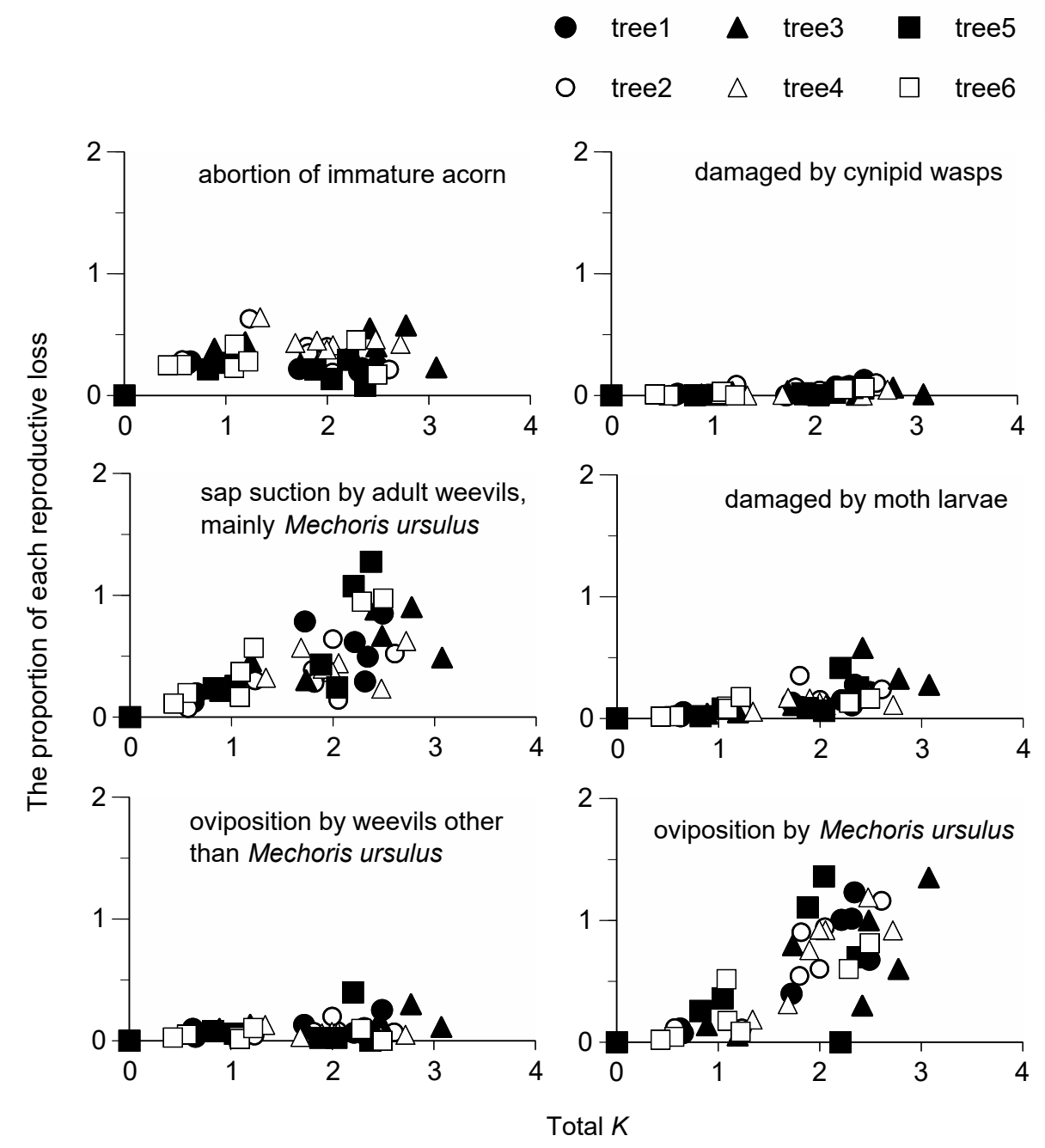

Online Resource 10 The relationship between the sum of reproductive loss during the pre-dispersal phase and the proportion of each reproductive loss for each individual over seven years.

Different letters indicate different individuals.

When the number of flowers was zero, the data were excluded. 